EESTI NSV TEADUSTE AKADEEMIA TOIMETISED, 26. KOIDE

KEEMIA * GEOLOOGIA, 1977, Nr. 1

ИЗВЕСТИЯ АКАДЕМИИ НАУК ЭСТОНСКОН ССР. ТОМ 26 ХИМИЯ * ГЕОЛОГИЯ. 1977, № 1

А.-М. МЮРИСЕПП, СИльвия РАНГ, О. ЭИЗЕН

удК $543.51: 547.314$

\title{
ДИССОЦИАТИВНАЯ ИОНИЗАЦИЯ
}

В гомологическом ряду $н$-алкинов ранее исследованы масс-спектры изомеров до $\mathrm{C}_{10}$, а также некоторых высших $н$-алкинов $\left[{ }^{1-5}\right]$. Установлено, что в сложном процессе их распада протекает изомеризация молекулярного иона. Перемешивание атомов водорода играет важную роль в ионах, возникших в результате многоступенчатого разложения [1-6].

В настоящей работе с целью выявления закономерностей диссоциативной ионизации молекул высших ацетиленовых углеводородов изучались электронноударные масс-спектры н-алкинов $\mathrm{C}_{11}-\mathrm{C}_{14}$. С целью проверки экспериментальной техники нами повторно исследовались H-алкины $\mathrm{C}_{8}-\mathrm{C}_{10}$. Полученные результаты хорошо согласовались с литературными данными $[1-3,5,7]$.

Масс-спектры снимались на приборе $\mathrm{MX}$-1303 при температуре ионизационной камеры и системы напуска $200{ }^{\circ} \mathrm{C}$ и энергиях ионизирующих электронов 50, 20, 14, 12 и 10 эв. Масс-спектры ведены в табл. 1 и 2.

Молекулы $н$-алкинов характеризуются слабой устойчивостью к воздействию электронного удара. При 50 эв стабильность молекулярного иона $\left(W_{M}\right)$ у 1 -ундецина и 1 -додецина примерно в 100 раз ниже, чем у соответствующих нормальных 1-алкенов. По мере перемещения тройной связи к центру углеродной цепи стабильность молекул $H$-алкинов к электронному удару увеличивается.

Распад молекулярных ионов с отщеплением алкильных групп или молекул алкенов ведет к образованию двух характеристических серий осколочных ионов с общей формулой $\left(\mathrm{C}_{n} \mathrm{H}_{2 n-3}\right)+\mathrm{c} m / e 67,81,95$ и т. д. и $\left(\mathrm{C}_{n} \mathrm{H}_{2 n-2}\right)^{+}$. с $m / e$ 68, 82 и т. д. Суммарная интенсивность пиков ионоь первой серии ( $\Sigma 67)$ составляет $20-50 \%$ от суммарного ионного тока, а ионов второй серии $(\Sigma 68)-10-20 \%$ (при 50 эв).

Основными продуктами первичного распада 1-, 2-, 3- и 4-алкинов являются ионы с $m / e$ 81, 95, 109 и 123 соответственно. Пик иона с $m / e 123$ у 4-изомера при 14 эв не преобладает в спектре, при снижении энергии ионизирующих электронов до 10 эв он становится максимальным. Эти ионы возникают, вероятно, по механизму, предложенному ранее для диссоциативной ионизации октинов, нонинов и децинов [ $\left.{ }^{1}\right]$.

Суть предложенного механизма заключается в разрыве $\varepsilon$-углеродуглеродной связи и в образовании ионов с шестичленной циклической структурой (рис. 1). Разрывы, приводящие к образованию пятичленных циклов с $m / e 67$ у 1 -алкинов, $m / e 81$ у 2 -алкинов, $m / e 95$ у 3 -алкинов и $m / e 109$ у 4-алкинов, вероятно, не являются основными. Эти ионы явля- 


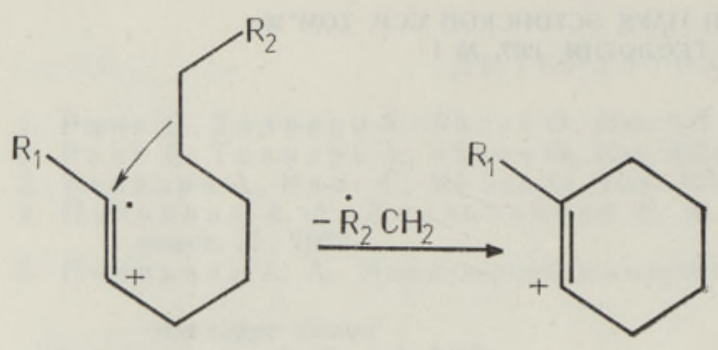

Рис. 1. Механизм образования иона с шестичленной циклической структурой. ются вторичными, так как образуются в основном из других осколочных ионов. Ионы с $m / e$ 95, 109, 123 и 137 соответственно у 1-, 2-, 3 и 4-алкинов, отвечающие образованию семичленного цикла, по своей интенсивности значительно слабее, чем сбответствующие ионы с шестичленным циклом.

Начиная с 4-изомеров характерными являются ионы, которые образуются при формальном $\alpha$-отрыве алкильного заместителя. При энергии ионизирующих электронов 14 эв пики этих ионов с $m / e 67$ и 81 являются максимальными соответственно в спектрах 4- и 5-изомеров. Равная вероятность разрыва двух $\alpha$-связей при распаде симметричных молекул 6-додецина и 7-тетрадецина приводит к значительному выходу осколков с $m / e 95$ и 109.

Радикальному отщеплению алкильной группы отвечают и ионы, образующиеся при $\beta$-разрыве. При энергии ионизирующих электронов 14 эв у 3 -изомеров $\beta$-разрыву соответствует ион с $\mathrm{m} / \mathrm{e} 67$ (интенсивность $95 \%$ от максимального пика), у 4-изомера - ион с $m / e$, 1 , у 5- и 6-изомеров - ионы с $m / e 95$ и 109.

Возникновение перегруппировочных ионов с $m / e$ 82, 96, 110 соответственно в спектрах $H$-1-, -2- и -3-алкинов связано с 1,8-миграцией атома водорода, протекающей с образованием восьмичленных промежуточных циклических структур, что впервые было показано Луфтманном и Шпителлером [3]. Эта реакция протекает только при наличии в молекуле достаточно длинной $\left(\geqslant \mathrm{C}_{9}\right)$ цепи алкильного заместителя. В спектрах $\mathrm{H}$-1и -2-додецинов этой реакции соответствуют максимальные пики перегруппировочных ионов, в спектрах 3- и 4-изомеров эти ионы c $\mathrm{m} / \mathrm{e}$ соответственно 110 и 124 по интенсивности значительно слабее.

Характерной особенностью спектров 5- и 6-алкинов является большая распространенность ионов с $m / e 54$, обязанных двукратной перегруппировке Мак-Лафферти (рис. 2). Из-за наличия первичного водо-

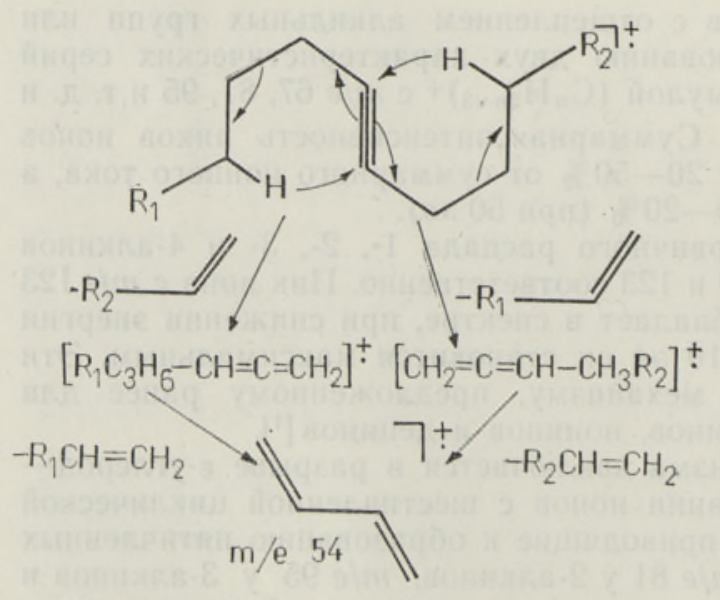

Рис. 2. Механизм образования иона с $m / e 54$. родного атома в $\gamma$-положении (в пропильной группе) у 4-изомеров данная реакция протекает со значительно меньшей вероятностью.

Осколочные перегруппировочные ионы в спектрах 6-додецина и 7-тетрадецина соответственно с $m / e 82$ и 96 отвечают формальному разрыву тройной связи и элиминированию атома водорода.

На основании проведенного исследования установлены количественные завнсимости интенсивностей пиков некоторых характери- 
стических ионов от числа атомов углерода в молекуле в виде уравнений типа $I=a e^{b n}$ (значения констант $a$ и $b$ приведены в табл. 3).

Влияние энергии ионизирующих электронов на процесс диссоциативной ионизации $н$-алкинов исследовалось более подробно на примере н-додецинов. По изменению интенсивности пика в зависимости от энергии ионизирующих электронов ионы, образующиеся при распаде $\boldsymbol{H}$-алкинов, можно разделить на три группы (рис. 3 ) :

1. Ионы, количество которых при понижении энергии ионизирующих электронов ниже 20 эв резко увеличивается. K этой группе принадлежат:

а) молекулярный ион (рис. $3 A$ ),

б) ионы первичного распада 1-, 2-, 3- и 4-изомеров с $m / e$ соответственно 81 (рис. 35 ), 95, 109 и 123, обладающие, по-видимому, шестичленной циклической структурой,

в) ионы, образующиеся в результате 1,8-миграции атома водорода и разрыва $\varepsilon$-связи в молекулах 1-, 2-, 3- и 4-изомеров с $m / e 82$ (рис. $3 B$ ) $, 96,110,124$,

г) ионы с $m / \mathrm{e} 82$ и 96 , отвечающие формальному разрыву тройной связи в центре симметричной молекулы $\left(\mathrm{C}_{12}\right.$ и $\mathrm{C}_{14}$ ) с потерей атома водорода (рис. $3 B$ ).

2. Вторичные осколочные ионы с $m / e 54,67,81$ и 95 (кривая изменения их относительных интенсивностей проходит через максимум при $14-35$ эв (рис. $35,3 B))$.

3. Ионы с $m / e ~ 27,29,39,41$ и 43 , интенсивность пиков которых увеличивается с ростом энергии ионизирующих электронов.
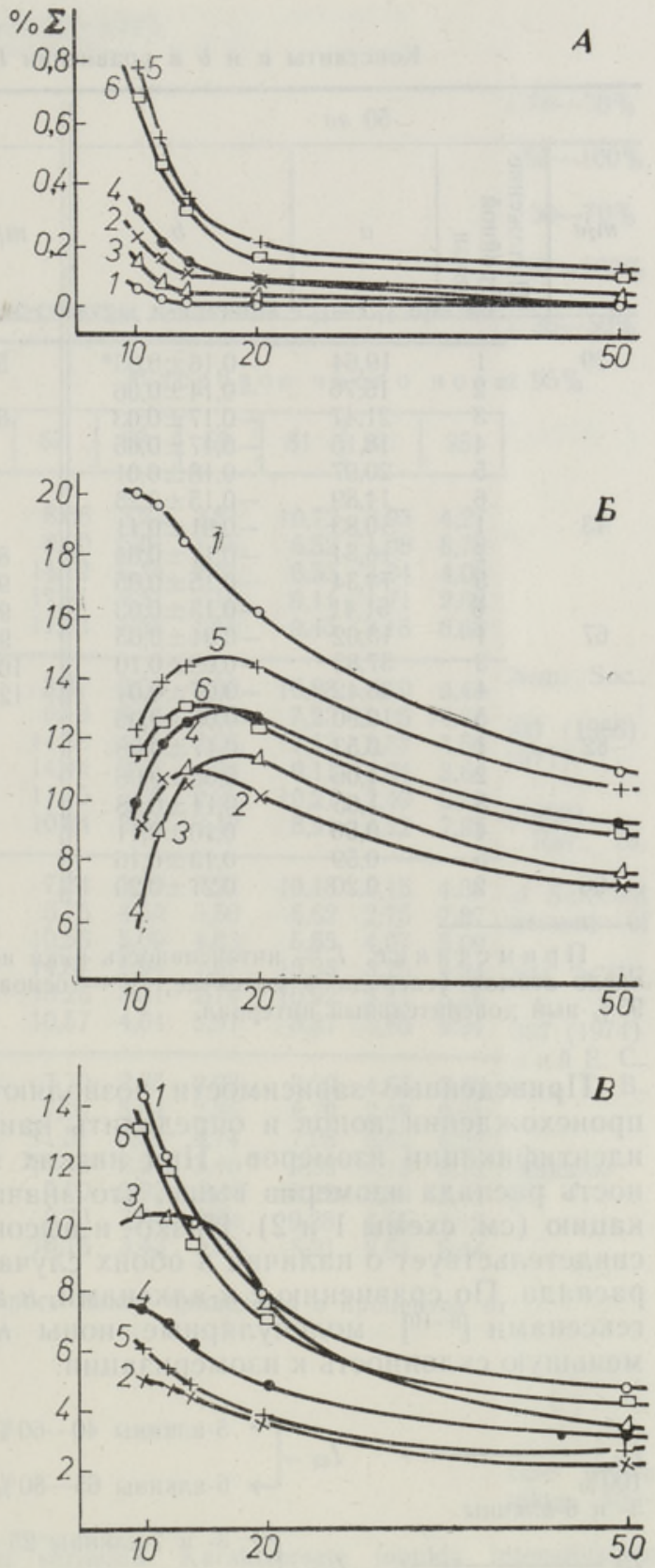

Рис. 3. Влияние энергии ионизирующих электронов на вероятность образования ионов в масс-спектрах н-додецинов. $A$ - молекулярный ион; $B$ - ион с $m / e 81 ; B-$ ион с $m / e 82$ 1 - 1-алкины, 2 - 2-алкины, 3 - 3-алкнны, 4 - 4-алкины, 5 - 5-алкины, 6 - 6-алкины. 
таблица 3

Константы $a$ и $b$ в уравнении $I=a e^{b n}$ для $\boldsymbol{k}$-алкинов

\begin{tabular}{|c|c|c|c|c|c|c|c|}
\hline \multicolumn{4}{|c|}{$50 \quad$ эв } & \multicolumn{4}{|c|}{$14 \quad 36$} \\
\hline$m / e$ & 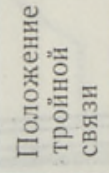 & $a$ & $b$ & $m / e$ & 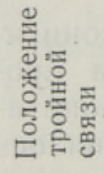 & $a$ & $b$ \\
\hline \multirow[t]{6}{*}{39} & 1 & 19,64 & $-0,16 \pm 0,03^{*}$ & 54 & 2 & 61,55 & $-0,24 \pm 0,69$ \\
\hline & 2 & 15,76 & $-0,14 \pm 0,06$ & & 5 & 177,72 & $-0,20 \pm 0,08$ \\
\hline & 3 & 21,47 & $-0,17 \pm 0,03$ & 67 & 1 & 31,09 & $-0,09 \pm 0,04$ \\
\hline & 4 & 18,15 & $-0,17 \pm 0,05$ & & 2 & 18,11 & $-0,10 \pm 0,08$ \\
\hline & 5 & 20,97 & $-0,18 \pm 0,01$ & & 3 & 67,96 & $-0,14 \pm 0,06$ \\
\hline & 6 & 14,89 & $-0,15 \pm 0,28$ & & 4 & 82,88 & $-0,13 \pm 0,02$ \\
\hline \multirow[t]{3}{*}{43} & 1 & 10,83 & $-0,01 \pm 0,11$ & & 5 & 19,24 & $-0,05 \pm 0,11$ \\
\hline & $\begin{array}{l}2 \\
5\end{array}$ & $\begin{array}{l}16,34 \\
74,34\end{array}$ & $\begin{array}{l}-0,11 \pm 0,04 \\
-0,15 \pm 0,05\end{array}$ & $\begin{array}{l}82 \\
95\end{array}$ & $\begin{array}{l}1 \\
2\end{array}$ & $\begin{array}{r}0,89 \\
32,78\end{array}$ & $\begin{array}{l}+0,20 \pm 0,03 \\
-0,03 \pm 0,03\end{array}$ \\
\hline & 6 & 51,41 & $-0,13 \pm 0,03$ & 96 & 6 & 73,96 & $-0,14 \pm 0,68$ \\
\hline \multirow[t]{3}{*}{67} & 1 & 13,02 & $-0,04 \pm 0,05$ & 96 & 2 & 0,15 & $+0,33 \pm 0,16$ \\
\hline & 3 & 37,83 & $-0,09 \pm 0,10$ & 109 & 3 & 76,98 & $-0,14 \pm 0,18$ \\
\hline & $\begin{array}{l}4 \\
5\end{array}$ & $\begin{array}{l}38,42 \\
19,90\end{array}$ & $\begin{array}{l}-0,07 \pm 0,04 \\
-0,05 \pm 0,06\end{array}$ & 123 & 4 & 83,83 & $-0,19 \pm 0,18$ \\
\hline 82 & 1 & 0,53 & $0,17 \pm 0,08$ & & & & \\
\hline & 2 & 1,06 & $0,06 \pm 0,06$ & & & & \\
\hline & $\begin{array}{l}3 \\
4\end{array}$ & $\begin{array}{l}1,05 \\
0,90\end{array}$ & $\begin{array}{l}0,11 \pm 0,08 \\
0,10 \pm 0,11\end{array}$ & & & & \\
\hline & 5 & 0,59 & $0,13 \pm 0,16$ & & & & 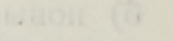 \\
\hline 96 & 2 & 0,20 & $0,21 \pm 0,20$ & & & & \\
\hline
\end{tabular}

Пр им еч ан ие. $I$ - интенсивность пика иона от полного ионного тока, $\% ; n-$ чнсло атомов углерода в молекуле; $e-$ основание натуральных логарифмов; * $95 \%$-ный доверительный интервал.

Приведенные зависимости позволяют сделать некоторые выводы о происхождении ионов и определить наиболее подходящие условия для идентификации изомеров. При низких энергиях электронов селективность распада изомеров выше, что значительно облегчает их идентификацию (см. схемы 1 и 2). Низко- и высоковольтные спектры сходны, что свидетельствует о наличии в обоих случаях общих основных механизмов распада. По сравнению с $\boldsymbol{H}$-алкенами, $\boldsymbol{H}$-алкил-циклопентенами и -циклогексенами $\left[{ }^{8-10}\right]$ молекулярные ионы $H$-алкинов имеют значительно меньшую склонность к изомеризации.

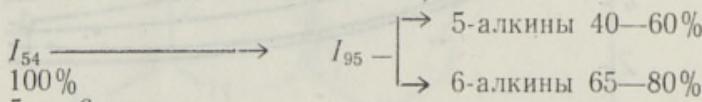

5- и 6-алкины

$I_{67}$

$100 \%$

3-, 4- и 7-алкины

$100 \%$

1-, 5- и 6-алкины

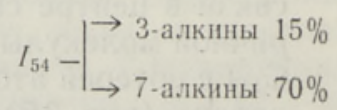

$I_{95}-\mid \begin{aligned} & \rightarrow \text { 5-алкины } 40-60 \% \\ & \rightarrow \text { 6-алкины } 65-80 \%\end{aligned}$

$I_{95} \longrightarrow 2$-алкины

$100 \%$

2-алкины

Схема 1. Идентификация изомерных $н$-алкинов $\mathrm{C}_{10}-\mathrm{C}_{14}$ при 50 эв. 
Масс-спектры и-алкинов $\mathrm{C}_{11}-\mathrm{C}_{14}$ при 14 эв

Таблица 2

\begin{tabular}{|c|c|c|c|c|c|c|c|c|c|c|c|c|c|c|c|c|c|c|c|c|c|c|c|c|c|c|}
\hline \multirow{2}{*}{\multicolumn{2}{|c|}{$\begin{array}{c}\text { Положе- } \\
\text { ние трой- } \\
\text { ной } \\
\text { связи }\end{array}$}} & \multicolumn{25}{|c|}{ Массовое число иона } \\
\hline & & 54 & 55 & 56 & 57 & 67 & 68 & 69 & 81 & 82 & 83 & 95 & 96 & 97 & 109 & 110 & 123 & 124 & 137 & 138 & 151 & 152 & 165 & 166 & 180 & 194 \\
\hline 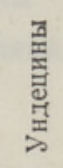 & $\begin{array}{l}1 \\
2 \\
3 \\
4 \\
5\end{array}$ & $\begin{array}{r}6,51 \\
2,73 \\
0,99 \\
5,00 \\
17,29\end{array}$ & $\begin{array}{l}5.92 \\
3,72 \\
3.91 \\
2.88 \\
6,60\end{array}$ & $\begin{array}{l}2,25 \\
0.68 \\
0.96 \\
0.42 \\
0,89\end{array}$ & $\begin{array}{l}2,96 \\
0.79 \\
0.58 \\
0.25 \\
0.59\end{array}$ & $\begin{array}{r}12,13 \\
6,45 \\
14,76 \\
19,25 \\
10,80\end{array}$ & $\begin{array}{l}5,71 \\
7,69 \\
9,95 \\
3,28 \\
5,17\end{array}$ & $\begin{array}{l}5,61 \\
2,00 \\
3,55 \\
2.07 \\
1,97\end{array}$ & $\begin{array}{r}19,37 \\
11,17 \\
9,27 \\
18,82 \\
14,39\end{array}$ & $\begin{array}{l}8,29 \\
5,21 \\
6,98 \\
4,39 \\
6,90\end{array}$ & $\begin{array}{l}1,74 \\
0,79 \\
1,70 \\
1,13 \\
0,77\end{array}$ & $\begin{array}{r}8,29 \\
22,63 \\
7,55 \\
6,19 \\
12,60\end{array}$ & $\begin{array}{l}2,96 \\
7,94 \\
2,13 \\
5,72 \\
4,65\end{array}$ & $\begin{array}{l}0,80 \\
1,43 \\
0,26 \\
0,69 \\
0,95\end{array}$ & $\begin{array}{r}2,25 \\
15,39 \\
13,73 \\
12,39 \\
4,14\end{array}$ & $\begin{array}{l}0,46 \\
2,85 \\
5,33 \\
3,70 \\
2,28\end{array}$ & $\begin{array}{r}0,29 \\
2,18 \\
6,86 \\
10,96 \\
2,48\end{array}$ & $\begin{array}{l}0,38 \\
0,80 \\
1,19 \\
0,42\end{array}$ & & & & $\begin{array}{l}0.002 \\
0.04 \\
0,12 \\
0.28 \\
0,81\end{array}$ & & & & \\
\hline 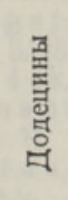 & $\begin{array}{l}1 \\
2 \\
3 \\
4 \\
5 \\
6\end{array}$ & $\begin{array}{r}5,57 \\
4,34 \\
0.86 \\
5,41 \\
14,76 \\
11,97\end{array}$ & $\begin{array}{l}3,89 \\
3,72 \\
2,70 \\
4,19 \\
4,92 \\
4,15\end{array}$ & $\begin{array}{l}1,97 \\
1,07 \\
0,48 \\
0,97 \\
0,64 \\
0,76\end{array}$ & $\begin{array}{l}2,44 \\
1,78 \\
0,71 \\
1,72 \\
0,42 \\
0,72\end{array}$ & $\begin{array}{r}11,55 \\
5.34 \\
11.56 \\
16.07 \\
11,00 \\
9.42\end{array}$ & $\begin{array}{l}5,44 \\
9.31 \\
5.90 \\
3,38 \\
5,25 \\
5,59\end{array}$ & $\begin{array}{l}5,31 \\
5,21 \\
2.08 \\
2,05 \\
3.06 \\
4,79\end{array}$ & $\begin{array}{l}18,47 \\
10,42 \\
10.82 \\
12,54 \\
14,28 \\
12,96\end{array}$ & $\begin{array}{r}10,22 \\
4,47 \\
10.33 \\
6.22 \\
4.92 \\
9,57\end{array}$ & $\begin{array}{l}3,58 \\
1,19 \\
1,45 \\
2,16 \\
1,00 \\
1,64\end{array}$ & $\begin{array}{r}8,49 \\
20,51 \\
9.10 \\
5,95 \\
8,86 \\
14,81\end{array}$ & $\begin{array}{l}4,51 \\
8,06 \\
4,18 \\
3,38 \\
5,75 \\
4,95\end{array}$ & & $\begin{array}{r}2,80 \\
6.82 \\
13,77 \\
5,00 \\
6,40 \\
5,11\end{array}$ & $\begin{array}{l}0,65 \\
268 \\
7,13 \\
2,45 \\
2,66 \\
2,80\end{array}$ & $\begin{array}{l}0,38 \\
0.74 \\
4,67 \\
8,52 \\
3.06 \\
0,97\end{array}$ & $\begin{array}{l}0,54 \\
1,75 \\
2,92 \\
1,09 \\
0,54\end{array}$ & $\begin{array}{l}0,89 \\
3,81 \\
1,94 \\
3,59 \\
1,77\end{array}$ & $\begin{array}{l}0,52 \\
0,27 \\
0,50 \\
0,28\end{array}$ & $\begin{array}{l}0,19 \\
0,41 \\
0,40\end{array}$ & & & $\begin{array}{l}0,01 \\
0,12 \\
0,04 \\
0,15 \\
0,36 \\
0,30\end{array}$ & & $i$ \\
\hline 总 & $\begin{array}{l}1 \\
2 \\
3 \\
4 \\
5 \\
6\end{array}$ & $\begin{array}{r}5,07 \\
3,74 \\
1,40 \\
3,93 \\
13,71 \\
10,9\end{array}$ & $\begin{array}{l}3,81 \\
2,88 \\
3,53 \\
3,55 \\
5,45 \\
3,76\end{array}$ & $\begin{array}{l}1,81 \\
1,45 \\
1,87 \\
0,48 \\
0,86 \\
0,62\end{array}$ & $\begin{array}{l}3,17 \\
2,21 \\
1,87 \\
0.70 \\
0,57 \\
0,71\end{array}$ & $\begin{array}{r}10,51 \\
5,84 \\
9,94 \\
14,21 \\
10,73 \\
10,31\end{array}$ & $\begin{array}{l}5,76 \\
7,79 \\
7,23 \\
2,30 \\
4.73 \\
5,79\end{array}$ & $\begin{array}{l}3,81 \\
4,41 \\
5,92 \\
1,44 \\
3,19 \\
5,08\end{array}$ & $\begin{array}{r}17,08 \\
10,30 \\
7,83 \\
14,21 \\
15,49 \\
12,37\end{array}$ & $\begin{array}{r}11,03 \\
5,47 \\
8,44 \\
9,11 \\
6,85 \\
7,07\end{array}$ & $\begin{array}{l}4,17 \\
2,59 \\
2,99 \\
2,06 \\
2,06 \\
2,24\end{array}$ & $\begin{array}{r}7,97 \\
14,75 \\
8,74 \\
7,65 \\
8,65 \\
11,78\end{array}$ & $\begin{array}{l}5,89 \\
6,68 \\
2,91 \\
6,56 \\
4,93 \\
5,60\end{array}$ & & $\begin{array}{r}2,90 \\
5,29 \\
11,15 \\
4,89 \\
3,39 \\
7,07\end{array}$ & $\begin{array}{l}0,91 \\
2.21 \\
5,12 \\
2,11 \\
3,19 \\
2,54\end{array}$ & $\begin{array}{l}0,48 \\
0,67 \\
2,39 \\
8,38 \\
0,19 \\
1,29\end{array}$ & $\begin{array}{l}0,31 \\
1,21 \\
4,41 \\
1,19 \\
0,85\end{array}$ & & & $\begin{array}{l}0,36 \\
1,57 \\
0,67 \\
0,61 \\
1,93\end{array}$ & $\begin{array}{l}0,22 \\
0,15 \\
0,28\end{array}$ & $\begin{array}{l}0,25 \\
0,14\end{array}$ & & $\begin{array}{l}0,01 \\
0,05 \\
0,07 \\
0,10 \\
0,6 \\
0,19\end{array}$ & \\
\hline 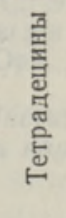 & $\begin{array}{l}1 \\
2 \\
3 \\
4 \\
5 \\
6 \\
7\end{array}$ & $\begin{array}{l}3,09 \\
1,90 \\
1,46 \\
5,03 \\
9.97 \\
8.81 \\
4,73\end{array}$ & $\begin{array}{l}1,57 \\
1,07 \\
2.06 \\
3.20 \\
4.89 \\
3,46 \\
1,28\end{array}$ & $\begin{array}{l}0.96 \\
0.58 \\
0,62 \\
0,59 \\
0,80 \\
0,72 \\
0,31\end{array}$ & $\begin{array}{l}1,34 \\
0.81 \\
1,15 \\
1,11 \\
1,21 \\
0,73 \\
0,48\end{array}$ & $\begin{array}{r}9,07 \\
4,57 \\
9,41 \\
13,25 \\
8,20 \\
8,81 \\
7,84\end{array}$ & $\begin{array}{l}4,65 \\
7,76 \\
7,67 \\
2,63 \\
3.74 \\
4,94 \\
4,36\end{array}$ & $\begin{array}{l}2,33 \\
2,41 \\
4.65 \\
3,65 \\
2,45 \\
4,10 \\
3,49\end{array}$ & $\begin{array}{r}18.61 \\
10,55 \\
8.13 \\
11.92 \\
13.52 \\
12.29 \\
10,21\end{array}$ & $\begin{array}{r}14,12 \\
6,86 \\
10,05 \\
7,99 \\
7,49 \\
8,60 \\
6,85\end{array}$ & $\begin{array}{l}3,76 \\
2,92 \\
3,99 \\
2,49 \\
1,76 \\
3,25 \\
3,08\end{array}$ & $\begin{array}{r}8,19 \\
19,89 \\
9,62 \\
7,88 \\
9,08 \\
11,27 \\
11,08\end{array}$ & $\begin{array}{c}7,74 \\
13,26 \\
3,56 \\
5,82 \\
5,81 \\
4,94 \\
10,70\end{array}$ & & $\begin{array}{r}2,97 \\
7,74 \\
12,40 \\
5,14 \\
2,98 \\
5,16 \\
10,58\end{array}$ & $\begin{array}{l}1,28 \\
4,57 \\
6,19 \\
2,37 \\
2,14 \\
3,46 \\
4,48\end{array}$ & $\begin{array}{l}0,67 \\
1,20 \\
2,95 \\
5,94 \\
2,83 \\
3,18 \\
2,59\end{array}$ & $\begin{array}{l}0,47 \\
0,65 \\
1,36 \\
3,54 \\
2,06 \\
1,21 \\
1,52\end{array}$ & $\begin{array}{l}0,21 \\
0,34 \\
0,38 \\
1,89 \\
4,81 \\
1,25 \\
0,97\end{array}$ & $\begin{array}{l}0,25 \\
0,50 \\
1,11 \\
2,06 \\
0,41 \\
0,52\end{array}$ & $\begin{array}{l}0.21 \\
0,56 \\
1,89 \\
0,84 \\
1,80 \\
1,02\end{array}$ & $\begin{array}{l}0,31 \\
0,35 \\
0,48 \\
0,42 \\
0,89 \\
0,33\end{array}$ & $\begin{array}{l}0,46 \\
1,28 \\
0,34 \\
0,54 \\
0,53 \\
2,6\end{array}$ & & & $\begin{array}{l}0,01 \\
0,04 \\
0.13 \\
0.17 \\
0,16 \\
0,23 \\
0.19\end{array}$ \\
\hline
\end{tabular}

Примеч а н ие: Интенсивности основных линий ( $>5 \%$ от максимального пика) приведены в процентах от полного ионного тока 
Масс-спектры $\boldsymbol{н}$-алкинов $\mathrm{C}_{11}-\mathrm{C}_{14}$ при 50 әв

\begin{tabular}{c}
$\begin{array}{c}\text { Положе- } \\
\text { ние трой- } \\
\text { ной } \\
\text { связи }\end{array}$ \\
\hline
\end{tabular}

\begin{tabular}{|c|c|c|c|c|c|c|c|c|c|c|c|c|c|c|c|c|c|c|c|c|c|c|c|c|c|c|c|}
\hline 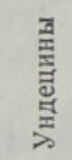 & $\begin{array}{l}1 \\
2 \\
3 \\
4 \\
5\end{array}$ & $\begin{array}{l}3.70 \\
4.90 \\
3,19 \\
4,20 \\
3,78\end{array}$ & $\begin{array}{l}4.97 \\
4.76 \\
3,63 \\
4.71 \\
4.03\end{array}$ & $\begin{array}{l}3,23 \\
4.01 \\
3,34 \\
3,46 \\
2,77\end{array}$ & $\begin{array}{l}9.28 \\
9,81 \\
9,42 \\
8,80 \\
7,44\end{array}$ & $\begin{array}{l}1,96 \\
1,52 \\
1,31 \\
1.27 \\
0.89\end{array}$ & $\begin{array}{l}9.01 \\
4.89 \\
6.88 \\
450 \\
2.40\end{array}$ & $\begin{array}{l}1.85 \\
3.89 \\
2.45 \\
3.14 \\
2.65\end{array}$ & $\begin{array}{r}4,50 \\
4.14 \\
1,31 \\
4.82 \\
13.89\end{array}$ & $\begin{array}{l}7,62 \\
7,52 \\
6,09 \\
6,28 \\
781\end{array}$ & $\begin{array}{l}2,08 \\
1,25 \\
1,22 \\
0,66 \\
1,06\end{array}$ & $\begin{array}{l}3.81 \\
2.41 \\
0,76 \\
0,32 \\
0,77\end{array}$ & $\begin{array}{r}8,66 \\
8,00 \\
14,72 \\
17,91 \\
11,33\end{array}$ & $\begin{array}{l}3,23 \\
5,01 \\
6,24 \\
2,51 \\
3,53\end{array}$ & $\begin{array}{l}3,81 \\
1,95 \\
2,61 \\
1,79 \\
1,51\end{array}$ & $\begin{array}{r}10,7 \\
6,5 \\
6,5 \\
9,1 \\
9,4\end{array}$ & $\begin{array}{l}3, \\
1,5 \\
3, \\
3, \\
1,7 \\
3,1\end{array}$ & $\begin{array}{l}93 \\
98 \\
, 34 \\
71 \\
15\end{array}$ & $\begin{array}{l}4,27 \\
8,72 \\
4,06 \\
2,62 \\
6,68\end{array}$ & $\begin{array}{l}1,39 \\
2,21 \\
0,92 \\
1,35 \\
1,89\end{array}$ & $\begin{array}{l}5,8 \\
3,2 \\
1,8\end{array}$ & & $\begin{array}{l}0,20 \\
0,76 \\
2,07 \\
0,83 \\
0,89\end{array}$ & $\begin{array}{l}0,12 \\
0,58 \\
2,76 \\
2,30 \\
0,95\end{array}$ & $\begin{array}{l}0,30 \\
0,26 \\
0,16\end{array}$ & 0,12 & $\begin{array}{l}0,01 \\
0,01 \\
0,05 \\
0,06 \\
0,30\end{array}$ \\
\hline
\end{tabular}

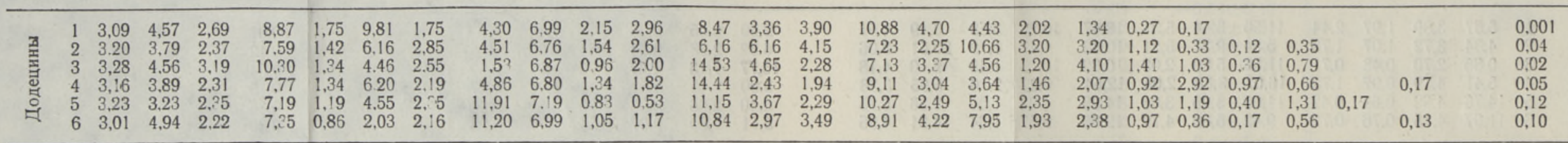

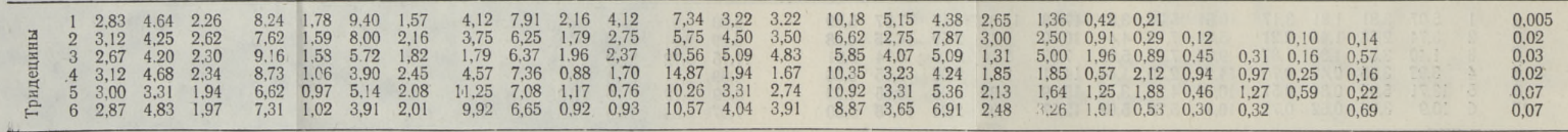

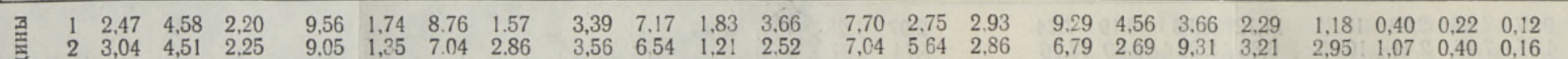

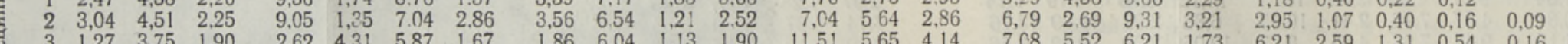

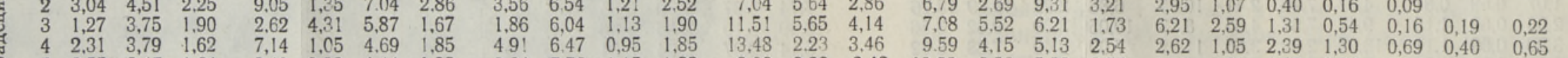

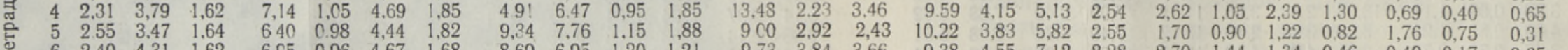

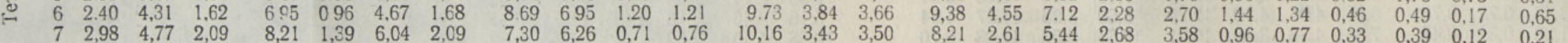

Примечан ие. Интенсивности основных линий ( $>5 \%$ от максимального пика) приведены в процентах от полного ионного тока. 


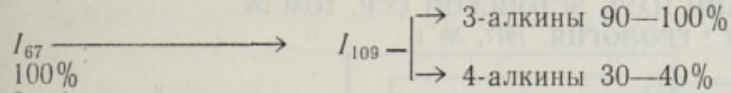

$$
\begin{aligned}
& \text { 3-, 4-алкины } \quad \longrightarrow \text { 1- и 4-алкины 16-40\% } \quad I_{67}-\longrightarrow \text { 1-алкины 50-70\% } \\
& I_{81} \longrightarrow \text { I } I_{54}-\longrightarrow \text { 5- и 6-алкины 70-100\% }
\end{aligned}
$$

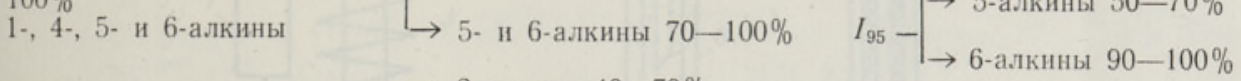

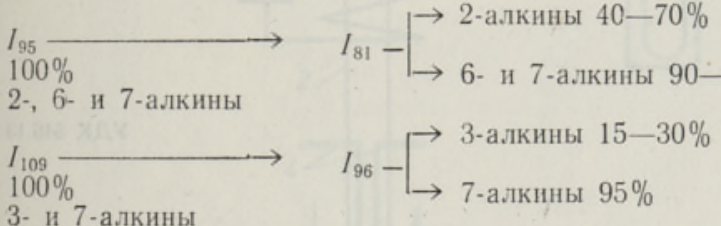

$$
\begin{aligned}
& I_{96}-\longrightarrow \text { 6-алкины } 30-50 \%
\end{aligned}
$$

Схема 2. Идентифнкация изомерных

\section{ЛИ ТЕРА Т У Р А}

1. Woodgat e, P. D., Mayer, K. K., D jer a s si, C., J. Amer. Chem. Soc., 94, 3115 (1972).

2. Dolejšek, Z., H a nuš, V., Vokač, K., Adv. Mass Spectrom., 3, 503 (1966).

3. Luftmann, H., Spiteller, G., Org. Mass Spectrom., 5, 1073 (1971).

4. Reed, R. J., Rev. Port Quim., 14, 43 (1972).

5. Rondeau, R. E., Harrah, L. A., J. Chem. Eng. Data, 13, 109 (1968).

6. Bursey, J. T., Bursey, M. M., Kingston, D. G. I., Chem. Rev., 73, 191 (1973).

7. Kendall, R. F., Ecclest on, B. H., Mass and Infrared Spectra of Selected Unsaturated Hydrocarbons and Oxygenates, United States Department of the Interior, Bureau of Mines, 1965.

8. Р анг С., М юрисепп А. М., Т ал в ари А., Лй йт а а М., Изв. АН ЭССР, Хим. Геол., 24, № 2, 95 (1975).

9. Т ал в а р и А., Р а н г С., Э й з е н О., Изв. АН ЭССР, Хим. Геол., 23, № 4, 307 (1974)

10. Р анг С., Эй зен О., Поляков а А. А., Лукашенко И. М., Бродский Е. С., Мюрисепп М. А., Синиярв Р. К., Вялиметс $М$. Т., Тийкмаа Т. В. ЖОрX, 8, № 10, 1993 (1972).

\section{Ннститут химии \\ Академии наук Эстонской ССР \\ Поступила в редакцию 15/V 1975}

\section{A.-M. MOORISEPP, Silvia RANG, O. EISEN}

\section{n-ALKUONIDE DISSOTSIATIIVNE IONISATSIOON}

Uurimuses võrreldakse $n$-alküünide $\mathrm{C}_{11}-\mathrm{C}_{14}$ massispektreid ja esitatakse nende fragmentatsiooni seaduspärasused ioniseerivate elektronide energia vahemikus $10-$ $50 \mathrm{eV}$.

Isomeersete alküünide spektrid on sarnased. Karakteersete ioonide intensiivsuste sõltuvus kolmiksideme asukohast molekulis võimaldab nende ühendite identifitseerimist.

\section{A.-M. MUURISEPP, Sylvia RANG, O. EISEN}

\section{DISSOCIATIVE IONIZATION OF $n$-ALKYNES}

Mass spectra of $n$-alkynes $\mathrm{C}_{11}-\mathrm{C}_{14}$ have been investigated at $10-50 \mathrm{eV}$ and correlated with the structure of molecules.

The mass spectra of positional isomers are similar, but differences in characteristic ion intensities enable their identification on the ground of their mass spectra. 